\title{
Screening of enzymatic activities for the depolymerisation of the marine bacterial exopolysaccharide HE800
}

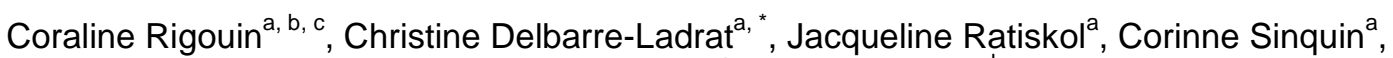 \\ Sylvia Colliec-Jouault ${ }^{\mathrm{a}}$ and Michel Dion ${ }^{\mathrm{b}}$
}

\footnotetext{
${ }^{a}$ Ifremer, Laboratoire de Biotechnologie et Molécules Marines, rue de l'lle d'Yeu, BP 21105, 44311 Nantes Cedex 3, France

${ }^{\mathrm{b}}$ Laboratoire de Biocatalyse, UMR-CNRS 6204, Biotechnologie, Biocatalyse, Bioregulation, Faculté des Sciences et des Techniques, Université de Nantes, 2 rue de la Houssinière, BP 92208, 44322 Nantes Cedex 3, France

c Present address : Department of Immunology and Microbiology, Rush University Medical Center, 1735W, Harrison Street, Chicago, IL 60610, USA
}

*: Corresponding author : Christine Delbarre-Ladrat, email address : $\underline{\text { Christine.Delbarre.Ladrat@ifremer.fr }}$

\begin{abstract}
:
The exopolysaccharide (EPS) HE800 is a marine-derived polysaccharide (from $8 \times 10^{5}$ to $1.5 \times 10^{6} \mathrm{~g} \mathrm{~mol}^{-1}$ ) produced by Vibrio diabolicus and displaying original structural features close to those of glycosaminoglycans. In order to confer new biological activities to the EPS HE800 or to improve them, structural modifications need to be performed. In particular, depolymerisation is required to generate low-molecular-weight derivatives. To circumvent the use of chemical methods that lack specificity and reproducibility, enzymes able to perform such reaction are sought. This study reports the screening for enzymes capable of depolymerising the EPS HE800. A large diversity of enzyme sources has been studied: commercially available glycoside hydrolases with broad substrate specificity, lyases, and proteases as well as growing microorganisms. Interestingly, we found that the genus Enterococcus and, more particularly, the strain Enterococcus faecalis were able to depolymerise the EPS HE800. Partial characterization of the enzymatic activity gives evidence for a random and incomplete depolymerisation pattern that yields low-molecular-weight products of $40,000 \mathrm{~g} \mathrm{~mol}^{-1}$. Genomic analysis and activity assays allowed the identification of a relevant open reading frame (ORF) which encodes an endo- $\mathrm{N}$-acetyl-galactosaminidase. This study establishes the foundation for the development of an enzymatic depolymerisation process.
\end{abstract}

Keywords: Polysaccharide-Enzymatic depolymerisation-Low-molecular-weight derivatives Enterococcus faecalis - Endo- $N$-acetyl-galactosaminidase 


\section{Introduction}

Polysaccharides are macromolecules produced by various organisms: fungi, plants, bacteria and animals. They are widely used in industry. Indeed, they display interesting functional and biological properties that allow their utilisation in many sectors, e.g., in detergents, textiles, adhesives, paper, paint, food, pharmaceuticals, cosmetics, oil and metal recovery (Sutherland 1998). For several years, interest in polysaccharides for biological applications has grown considerably especially in therapeutics as high added value products. Bacterial exopolysaccharides (EPS), compared to polysaccharides from other origins, tend to be more advantageous for commercial applications in regard to their production and availability. Therefore, new polysaccharides from bacterial origin, which exhibit new and interesting properties for biological applications, are today sought.

Under-exploited resources of marine environment become increasingly interesting for a biotechnological use. In particular, marine bacterial diversity may lead to the discovery and the characterization of innovative molecules (Boeuf and Kornprobst 2009; Guezennec 2002). Along with the isolation of new bacterial strains, a screening for EPS production was performed on samples recovered from deep sea hydrothermal ecosystems (Guezennec 2002). Among these mesophilic heterotrophic strains, several EPS producers have been described: they belong to the genera Alteromonas, Pseudoalteromonas and Vibrio (Cambon-Bonavita et al. 2002; Raguenes et al. 1996, 1997a,b, 2003). Some of these EPSs have been structurally characterised (Roger et al. 2004; Rougeaux et al. 1999a; Rougeaux et al. 1998, 1999a,b); most of them display uronic acid contents ranging from $10 \%$ to $40 \%$ and high molecular weight around $10^{6} \mathrm{~g} \mathrm{~mol}^{-1}$. Some of them are also sulfated (Roger et al. 2004; Rougeaux et al. 1998, 1999a).

In particular, Vibrio diabolicus was isolated from the polychaete annelid Alvinella pompejana (Raguenes et al. 1997a). In an aerobic marine-based medium complemented with glucose, this organism produces the EPS HE800, an innovative hyaluronic acid-like EPS. The structure of this high molecular weight polysaccharide (from 0.8 to $1.5 \times 10^{6} \mathrm{~g} \mathrm{~mol}^{-1}$ ) has been elucidated (Rougeaux et al. 1999b), and consists of a linear tetrasaccharidic repeating unit composed of two $N$-acetyl-hexosamine and two glucuronic acid residues:

$$
\text { [ 3)- } \beta \text {-D-Glc } p \text { NAc- }(1 \rightarrow 4)-\beta-D-G l c p A-(1 \rightarrow 4)-\beta-D-G l c p A-(1 \rightarrow 4)-\alpha-D-G a l p N A c-(1 \rightarrow]_{\mathrm{n}}
$$

Structurally related to hyaluronic acid, the EPS HE800 may exhibit some similar biological properties: the biological activity of this bacterial polysaccharide in its native form has been successfully investigated in bone regeneration (Zanchetta et al. 2003). Moreover, its original 
structural features showing hexosamines and uronic acids make it a relevant biotechnological new molecule with glycosaminoglycan-like biological activities.

To obtain glycosaminoglycan-like derivatives from a native polysaccharide requires some structural modifications such as depolymerisation and sulfation. Therefore, new effective processes have to be developed to modify glycopolymers and generate active biomolecules. Our team is currently working on chemical methods to confer new or improved biological activities to the EPS HE800 (Colliec-Jouault et al. 2001; Guezennec et al. 1998; Senni et al. 2011). Because of their low specificity, chemical methods of modification can be easily used with most of the polysaccharides. In particular, free radical depolymerisation is usually performed to generate low-molecular-weight fractions and has been applied to glycosaminoglycans (Volpi 1994) and fucans (Nardella et al. 1996). Although these chemical reactions are effective, they are difficult to control, lack selectivity and may involve undesirable side reactions such as desulfation (Guezennec et al. 1998; Karlsson and Singh 1999) or formation of anhydrosugars (Shively and Conrad 1976). Therefore, alternative enzymatic methods for polysaccharide modification are being investigated to circumvent these drawbacks. The use of enzymes obviously allows great specificity, a better control of the reactions and leads to polysaccharidic derivatives with reproducible structural features by using friendly environmental conditions. However, since enzymes are highly specific towards a substrate, new glycopolymer molecules may require a new screening step to find active enzymes.

In this study, we report the screening for enzymes capable of depolymerising the EPS HE800 with the goal of generating bioactive low molecular weight polysaccharidic derivatives. A large diversity of enzyme sources has been studied: active enzymes have been searched among commercially available enzymes and some microorganisms. Interestingly, we found that only one bacterial genus, Enterococcus and more particularly the species Enterococcus faecalis, was able to depolymerise the EPS HE800. This study establishes the foundation for the development of an enzymatic depolymerisation process.

\section{Materials and methods}

\section{Commercial enzymes and microbial strains}

The origin of tested enzymes and microbial strains are respectively given in Tables 1 and 2 . Enzymes were tested at $\mathrm{pH} 6$ and $\mathrm{pH} 7.5$ and were prepared at $10 \mathrm{mg} \mathrm{ml}^{-1}$ or twice diluted when enzyme was supplied in liquid. 
Microorganisms were grown in the presence of the polysaccharide HE800 within the appropriate medium. Zobell (33.3 $\mathrm{g} \mathrm{l}^{-1}$ aquarium salt [Instant Ocean], $4 \mathrm{~g} \mathrm{l}^{-1}$ tryptone, $1 \mathrm{~g} \mathrm{l}^{-1}$ yeast extract) and marine minimum medium (33.3 $\mathrm{g} \mathrm{l}^{-1}$ aquarium salts, $6.8 \mathrm{~g} \mathrm{l}^{-1} \mathrm{Na}_{2} \mathrm{HPO}_{4}, 3 \mathrm{~g} \mathrm{l}^{-1} \mathrm{KH}_{2} \mathrm{PO}_{4}, 1 \mathrm{~g} \mathrm{l}^{-1}$ $\mathrm{NH}_{4} \mathrm{NO}_{3}, 10 \mathrm{mM} \mathrm{MgSO}$, $0.1 \mathrm{~g} \mathrm{l}^{-1} \mathrm{KBr} \mathrm{pH}$ 7) were used for marine bacteria. Luria Broth (LB) (10 $\mathrm{g} \mathrm{l}^{-1}$ tryptone, $5 \mathrm{~g} \mathrm{l}^{-1}$ yeast extract, $5 \mathrm{~g} \mathrm{l}^{-1} \mathrm{NaCl}, \mathrm{pH}$ 7.5) and $\mathrm{M} 9$ minimum medium $\left(6.8 \mathrm{~g} \mathrm{l}^{-1}\right.$ $\mathrm{Na}_{2} \mathrm{HPO}_{4}, 3 \mathrm{~g} \mathrm{l}^{-1} \mathrm{KH}_{2} \mathrm{PO}_{4}, 0.5 \mathrm{~g} \mathrm{l}^{-1} \mathrm{NaCl}, 1 \mathrm{~g} \mathrm{l}^{-1} \mathrm{NH}_{4} \mathrm{Cl}, 0.02 \mathrm{~g} \mathrm{l}^{-1} \mathrm{CaCl}_{2}, 10 \mathrm{mM} \mathrm{MgSO}$, $\mathrm{pH}$ 7.5) were used for the other strains. Positive controls for growth (culture with $2 \mathrm{~g} \mathrm{l}^{-1}$ glucose as carbon source) were added when minimal medium was used.

Polysaccharide preparation and incubation with commercial enzymes, bacterial strains or cellular extracts

The polysaccharide HE800 was produced as previously described (Rougeaux et al. 1999b) and isolated from the culture broth by centrifugation and ultrafiltration using a $100 \mathrm{kDa}$ membrane (OMEGA) on a Masterflex system (Cole-Parmer). The purified extract was finally lyophilised. Polysaccharide fibres were then slowly dissolved in water or buffer at a final concentration of 4 $\mathrm{mg} \mathrm{ml}^{-1}$ and were sterilised on a 0.2- $\mu \mathrm{m}$ membrane (Sterivex, Millipore).

One volume of the EPS HE800 sterile solution and one volume of twice concentrated culture medium were mixed. An overnight culture of the tested microorganism was used to inoculate the mixture. Negative controls (incubations without EPS HE800 or bacterial strain) were included. Reaction mixtures were shaken at $25^{\circ} \mathrm{C}, 30^{\circ} \mathrm{C}$ or $37^{\circ} \mathrm{C}$ depending on the biological sample requirement for up to 7 days. Upon incubation, aliquots were removed every $24 \mathrm{~h}$, heated at $100^{\circ} \mathrm{C}$ for $10 \mathrm{~min}$, centrifuged at $13,000 \mathrm{xg}$ and the supernatants were kept at $-80^{\circ} \mathrm{C}$ until polysaccharide analysis using agarose gel electrophoresis and size exclusion chromatography-multi-angle laser light (SEC-MALS).

One volume of the lysate or culture supernatant was added to one volume of a solution of EPS HE800 at $4 \mathrm{mg} \mathrm{ml}^{-1}$. Negative controls (incubations without EPS HE800 or without extract) were included. Reactions were performed at $37^{\circ} \mathrm{C}$; aliquots were collected after $4 \mathrm{~h}$ of incubation and subsequently every $24 \mathrm{~h}$ and were kept at $-80^{\circ} \mathrm{C}$ until analysis for polysaccharide depolymerisation on agarose gel electrophoresis as well as by SEC-MALS.

HE800 was consequently tested at $2 \mathrm{mg} \mathrm{ml}^{-1}$ final concentration.

\section{Enzyme localization}

Enterococcus faecalis (collection of Nantes Hospital) was grown up to the end of the exponential phase in LB medium without EPS HE800. Cells were harvested after centrifugation at 13,000xg 
for $10 \mathrm{~min}$, resuspended and concentrated ten times in $50 \mathrm{mM}$ phosphate buffer $(\mathrm{pH} 7.5)$. Supernatant was filtrated on a $0.2-\mu \mathrm{m}$ membrane and ten times-concentrated using a 10,000-Da Viva Spin column (Sartorius). Concentrated cells and supernatant were incubated separately with the EPS HE800 ( $2 \mathrm{mg} \mathrm{ml}^{-1}$ final) at $37^{\circ} \mathrm{C}$ for several days. Samples were removed every $24 \mathrm{~h}$ and were analyzed for HE800 depolymerisation using agarose gel electrophoresis and SEC-MALS.

\section{Preparation of cell lysate}

For the cell lysis, culture medium was centrifuged at 13,000xg for $10 \mathrm{~min}$ and the cells were washed once in lysis buffer (50 mM phosphate buffer $\mathrm{pH} 7.9,100 \mathrm{mM} \mathrm{NaCl})$. Bacterial pellet was resuspended in 1/50 volume of centrifuged broth with cold lysis buffer to be 50 times concentrated. Lysozyme ( $2 \mathrm{mg} \mathrm{ml}^{-1}$ ) $10 \mathrm{mM}$ EDTA, $5 \mathrm{mM}$ benzamidine, $0.25 \mathrm{mM}$ PMSF, 0.001 $\mathrm{U} \mu \mathrm{l}^{-1}$ benzonase and $0.02 \%$ sodium azide were added and the mixture was incubated for $45 \mathrm{~min}$ at $25^{\circ} \mathrm{C}$ with shaking. The cells were then disrupted by sonication $(5 \mathrm{~min}$ at $40 \%$ amplitude repeated five times). After centrifugation, the supernatant was collected and called lysate.

\section{Expression and activity of $E$. faecalis enzymes}

EF3023 (NCBI reference sequence NP_816637) was kindly provided by Magnus Hook (Texas A\&M University Health Science Center, Houston, TX, USA). The strain Escherichia coli XL1 (pQE30-EF3023) expresses a truncated form of the protein EF3023 without the peptide signal and the cell wall anchoring domains. Expression and purification were carried out as previously described (Sillanpää et al. 2004). Autolysin EF0799 (NP_814543) was provided by Pr. McArthur (Université Paris 6, Paris, France). The strain E. coli BL21(pEt-AtlA) expresses the full length of EF0799. Expression and purification were performed as previously described (Eckert et al. 2006). EF1800 (NP_815498) was purchased from New England Biolabs (Ref. P0733). Enzyme activity was measured on the substrate $\mathrm{HE} 800$ upon incubation at $37^{\circ} \mathrm{C}$ in a reaction mixture containing the purified enzyme, $1 \mathrm{mg} \mathrm{ml}^{-1}$ EPS HE800 and 50mM phosphate buffer $\mathrm{pH}$ 7.9. For EF1800, an activity assay was performed at $37^{\circ} \mathrm{C}$ during $72 \mathrm{~h}$ with $1 \mathrm{mg} \mathrm{ml}^{-1}$ of EPS HE800 preheated at $100^{\circ} \mathrm{C}$ for $10 \mathrm{~min}$ in the NEB denaturation buffer provided with the enzyme $(0.5 \% \mathrm{SDS}, 40 \mathrm{mM}$ DTT). Depolymerisation was controlled by agarose gel electrophoresis and SEC-MALS.

\section{Electrophoretic analysis}

Analysis was performed by agarose electrophoresis and revealed with Stains all (1-ethyl-2-[3-(1ethylnaphtho[1,2-d]thiazolin-2-ylidene)-2-methylpropenyl]naphtho[1,2-d]thiazolium (Sigma)) as previously described (Rigouin et al. 2009). 


\section{SEC-MALS analysis}

Molecular weight of the polysaccharide was determined by size exclusion chromatography combined with a multi-angle laser light scattering detector (SEC-MALS).

The system consisted in a column (PL aquagel-0H, Varian), a pump and an injector (Kontron Instrument). Elution was performed at $1 \mathrm{ml} \mathrm{min}^{-1}$ with $0.1 \mathrm{M}$ ammonium acetate filtrated on a 0.1$\mu \mathrm{m}$ membrane. A refractive index (RI) detector (Hitachi L2490) and a MALS detector (miniDawn Heleos II $^{\mathrm{TM}}$; Wyatt) were coupled on-line. Samples were centrifuged and filtrated on a $0.45 \mu \mathrm{m}$ membrane prior to injection $(100 \mu \mathrm{l})$. Data for molecular weight determinations and conformation were analyzed with Astra software (Wyatt) based on a $\mathrm{dn} / \mathrm{dc}$ of 0.145 . The numberaverage molecular weight $\left(M_{\mathrm{n}}\right)$, the weight-average molecular weight $\left(M_{\mathrm{w}}\right)$, and the polydispersity index $\left(M_{\mathrm{w}} / M_{\mathrm{n}}\right)$ of the samples were determined.

\section{Results}

\section{Screening of depolymerising activities}

In this study, we tested a large diversity of biological samples for their ability to depolymerise the EPS HE800.

A total of 38 commercially available enzymes were tested in the presence of the EPS HE800 at pH 6 and pH 7 (Table 1). These enzymes are glycoside hydrolases and polysaccharide lyases with different substrate specificities, but also proteases since some of them such as papain, pronase and pepsin have been shown to break down chitin (Kumar and Tharanathan 2004; Kumar et al. 2004; Vishu Kumar et al. 2007a,b). Despite this broad diversity, none of the tested enzymes was found to depolymerise the EPS HE800 (data not shown).

Then, the screening on bacteria was performed since a lot of them produce several different endoglycanases. Various strains were chosen with regard to their marine environment or because of their described capacity to produce diversified glycoside hydrolase activities. Each strain was tested in appropriate growth medium (Table 2). Two culture conditions were carried out: in the first, a culture in minimal medium using the EPS HE800 as the only carbon source was performed in order to identify the potential use of EPS HE800 as a substrate for growth. Under these conditions, none of the strains grew. In the second, depolymerisation was assessed upon culture in a rich medium supplemented with the EPS HE800. Culture supernatants were analysed for polysaccharide degradation by agarose gel electrophoresis since this method has proven to be appropriate to get a rapid result (Rigouin et al. 2009). At the beginning of the incubation with the 
E. faecalis SP1 strain, the EPS HE800 pattern appeared as a broad smear on the agarose gel. After $48 \mathrm{~h}$ of incubation, a shift in the migration pattern was observed indicating an increased mobility and suggesting a depolymerisation. Lately, a depolymerisation was also detected with a strain of E. faecium and with another strain of E. faecalis (V583) (data not shown). The distance of migration of a polysaccharide submitted to electrophoresis on an agarose gel depends on both the global charge and the molecular weight of the polysaccharide. To check whether the molecular weight of the EPS HE800 decreased, the samples were analysed by SEC-MALS. For E. faecalis SP1, a progressive decrease in EPS HE800 molecular weight was observed with time and after 6 days of culture the molecular weight of HE800 decreased by half to reach 748,000 $\mathrm{g} \mathrm{mol}^{-1}$.

\section{Characterisation of the biocatalyst}

Further investigations were carried out to characterize the biocatalyst produced by E. faecalis SP1. Culture was performed in a rich medium without the HE800; at the end of the exponential phase of growth, cells and supernatant were separated, and both concentrated. Culture supernatant and cellular extracts obtained after cell lysis were incubated with the EPS HE800 under bacteriostatic conditions (sodium azide added). Samples were withdrawn during incubation and analysed for depolymerisation using agarose gel electrophoresis and SEC-MALS. No depolymerisation occurred with the culture supernatant; activity was only found in the cellular fraction (Fig. 1A). SEC-MALS analysis shows that the depolymerisation reached a plateau after a 72-h incubation at $42,000 \mathrm{~g} \mathrm{~mol}^{-1}$ (Fig. 1B) suggesting that the biocatalyst was not active anymore on the polysaccharide after this time. Additional experiments confirmed that it was the result of an enzymatic process: (i) the addition of proteases inhibitors helped to enhance the reaction of depolymerisation, resulting likely from a protection from proteases; (ii) an incubation at $70^{\circ} \mathrm{C}$ during $20 \mathrm{~min}$ to trigger enzyme denaturation led to the inhibition of the reaction of depolymerisation (data not shown). Therefore, the catalyst responsible for the depolymerisation seems to be an enzyme associated to the cells.

\section{Detailed analysis of elution profiles of size exclusion chromatography}

SEC-MALS was carried out on the samples withdrawn upon kinetics in order to get more detailed information on the depolymerisation process (Fig. 2). The decrease in $M_{\mathrm{w}}$ is depicted by the progressive shift towards higher elution times (RI, bottom plots). Besides the initial time, the elution profiles are characterized by a main peak delayed in time throughout the kinetic course. The molecular weight distribution (upper plot) is characterized by a downward curvature in the high molecular weight range, corresponding likely to aggregates. Then the curves become linear 
and overlap for the different samples. Such a profile is expected for polysaccharide preparations differing only in the molecular weight distribution. For each sample, the polydispersity index $\left(M_{\mathrm{w}} / M_{\mathrm{n}}\right)$ which expresses the molecular weight distribution of the polysaccharide in a fraction, never exceeded the value of 2 (data not shown), suggesting that the degradation products within each sample are also homogeneous. Taken together, those results suggest that the depolymerisation occurred in a random manner rather than in a processive one upon which heterogeneous fractions would be produced.

In a random enzymatic depolymerisation, the molecular weight of the polysaccharide should decrease with time according to the equation: $M_{\mathrm{w}}(t)^{-1}=M_{\mathrm{w}}(t=0)^{-1}+k t$, where $k$ is the kinetic rate constant of the depolymerisation process, $M \mathrm{w}(t)$ the molecular weight at time $t$ and $M_{\mathrm{w}}(t=0)$ is the molecular weight at initial time (Roubroeks et al. 2001). Figure 3 displays a straight curve up to $72 \mathrm{~h}$ confirming that the degradation occurs at a constant rate $\left(2 \times 10^{-7} \mathrm{~h}^{-1}\right)$ and in a random manner. A close kinetic rate constant $\left(1 \times 10^{-7} \mathrm{~h}^{-1}\right)$ was found when E. faecalis V583 was used, suggesting that bacterial strains belonging to the same species show the same depolymerisation activity on HE800.

\section{Genome analysis and protein candidates}

E. faecalis V583 genome has been sequenced (Paulsen et al. 2003) and made available under number NC_004668 (NCBI). Since this strain is, as E. faecalis SP1, able to depolymerise the EPS HE800, we identified nine open reading frames (ORFs) corresponding to endoglycanases or lyases that might be involved in this catalysis (Table 3). Taking into account the EPS HE800 chemical structure, seven ORFs were retained for further studies. Among them, three were produced in the laboratory: EF3023, EF0799 and EF1800. First, as described by Sillanpää et al. (2004), we successfully expressed in E. coli the protein encoded by the gene EF3023. This enzyme is a putative hyaluronate lyase and has been described to be anchored to the cell wall. The protein EF0799 (altA) is an endo- $N$-acetylglucosaminidase active on the peptidoglycan. It was also successfully purified in our lab as previously described (Eckert et al. 2006). However, none of EF3023 or EF0799 expressed proteins showed the expected activity on the EPS HE800 (data not shown). The protein encoded by the gene EF1800 is an endo- $\alpha-N$-acetyl-galactosaminidase. The gene carries a signal peptide and a bacterial Ig-like domain (group 4) found among bacterial surface proteins. When following New England Biolabs (NEB) recommendations, the incubation of the enzyme with the EPS HE800 led to a significant depolymerisation as shown by the agarose gel electrophoresis and SEC-MALS: a shift of the elution peak toward lower molecular weights 
occurred during the incubation (Fig. 4). Such results indicate that the protein EF1800 might be the enzyme involved in the depolymerisation of the HE800 by E. faecalis.

\section{Discussion}

In this study, we carried out a large screening in order to find enzymatic activities depolymerising the polysaccharide HE800. The EPS HE800 is of great biotechnological interest in both its native and its depolymerised form; therefore, finding enzymes capable of catalyzing the depolymerisation opens a new way for developing attractive bioprocesses for the production of tailor-made EPS derivatives.

Two major sources of biological samples were tested: commercial enzymes and bacterial strains. Enzymes were chosen among commercially available glycoside hydrolases with broad substrate specificity. Hyaluronidases were studied because of the structural similarity of the EPS HE800 with hyaluronic acid. No depolymerisation was observed with these commercial enzymes showing that the EPS HE800 exhibits a high structural specificity. Among bacterial strains, none of the strains from deep-sea hydrothermal vents, as well as none of the other deep-sea marine Vibrio strains was active. Bacteria from another atypical environment (Bogoria lake in Kenya), characterized by high salinity/alkalinity, and high temperature were also examined. Most of them belong to the genus Bacillus, which so far has proved to be a good producer of endoglycosidases (Nankai et al. 1999; Sutherland 1999) but again none of them revealed activity. Infectious bacterial strains from human samples were considered because of their natural ability to produce enzymes active on glycosaminoglycans (Stern et al. 2007). In fact, it is within this group that we found a bacterial genus capable of depolymerising the EPS HE800. E. faecalis SP1, as well as E. faecalis V583 and E. faecium were the only strains, among those tested, that led to a depolymerisation of the EPS HE800.

The reaction of depolymerisation with the concentrated cell lysate gave rise to final products reaching a quite low molecular weight of $40,000 \mathrm{~g} \mathrm{~mol}^{-1}$, which is however far from the number of potential cleavage sites. The conformation of the polysaccharide may be of great relevance for the modulation of this reaction. Indeed, the analysis of the polysaccharide in the reaction conditions gave evidence for aggregated chains inside the molecule (data not shown). Efforts have still to be done to promote the unfolding of the HE800 during the reaction in order to facilitate the access of the enzyme to other sites of the polysaccharide. Alternatively, this incomplete reaction could be also due to the enzyme denaturation throughout incubation. Whether this enzyme is able to 
depolymerise the EPS HE800 down to one repeated unit remains to be determined but there is likely one site of cleavage per repeated unit.

Among the enzymes annotated in the genome of E. faecalis, the EF1800 exhibits a HE800 depolymerising activity under specific conditions: substrate must be prepared in the denaturation buffer and heated; this may facilitate the accessibility of enzyme as discussed above. The enzyme has been described to catalyze the liberation of $O$-glycan from glycoproteins and more specifically to release core1-disaccharide from core1- $p$ NP $(\beta-G a l-(1 \rightarrow 3)-\alpha-G a l N A c-p N P)$, trisaccharide from core2- $p N P(\beta-G a l-(1 \rightarrow 3)-[\beta-G l c N A c-(1 \rightarrow 6)]-\alpha-G a l N A c-p N P)$ and tetrasaccharide from Galcore2- $p$ NP $(\beta-$ Gal- $(1 \rightarrow 3)-[\beta-G a l-(1 \rightarrow 3)-\beta-G l c N A c-(1 \rightarrow 6)]-\alpha-G a l N A c-p N P)$ (Goda et al. 2008) but also core3-disaccharide from $\beta-$ GlcNAc-( $1 \rightarrow 3)-\alpha-G a l N A c-p N P$ (Koutsioulis et al. 2008). Although those motifs are not entirely found in the sequence of the HE800, the presence of $\alpha$ GalNAc could be sufficient to entail the cleavage by this enzyme that displays broad substrate specificity. On the EPS HE800, the activity might correspond to a non processive pattern in which the enzyme is released from the substrate after each cleavage and binds randomly to another site in the molecule chain. Since we obtained products with homogeneous molecular weight, this agrees with the expected non processive enzymatic behaviour. Moreover, this endoglycosidase carries a peptide signal and a bacterial Ig-like domain which are hallmark signs of a surface protein; this agrees with our experiments since we have shown that the enzyme is associated to the cell. Therefore, this endo- $\alpha-N$-acetyl-galactosaminidase is likely to be responsible for the depolymerisation we measured with the cells of E. faecalis.

This work shows the difficulty to find an enzyme active on an unusual polysaccharidic molecule. Indeed, polysaccharide structural features are complex since they rely on multiple diversities : diversities of residues, of glycosidic linkages (regio- and sterero-isomers) and of glycosidic configurations (Bohn and Bemiller 1995). It also shows the fruitful strategy of the screening of bacteria because of their high number of endoglycosidases activities. It should be noted that the enzyme EF1800 was not commercially available at the start of the study. The bacterial screening allowed us to look for and identify this particular enzyme.

The future objectives will be to clearly identify its cleavage site on the EPS HE800 and to enhance its activity by directed evolution in order to obtain an efficient enzymatic tool.

\section{Acknowledgements}


The authors thank Dr. Jocelyne Caillon from Nantes Hospital who provided the Enterococcus faecalis SP1 strain. This work was made possible through Coraline Rigouin's fellowship from Ifremer and "Région Pays de la Loire". 


\section{References}

Boeuf G, Kornprobst J-M (2009) Biodiversité et chimiodiversité marines. Biofutur 301: 28-32

Bohn JA, Bemiller JN (1995) (1-->3)-[beta]--Glucans as biological response modifiers: a review of structure-functional activity relationships. Carbohydr Polym 28: 3-14

Cambon-Bonavita MA, Raguenes G, Jean J, Vincent P, Guezennec J (2002) A novel polymer produced by a bacterium isolated from a deep-sea hydrothermal vent polychaete annelid. J Appl Microbiol 93: 310-315

Colliec-Jouault S, Chevolot L, Helley D, Ratiskol J, Bros A, Sinquin C, Roger O, Fischer AM (2001) Characterization, chemical modifications and in vitro anticoagulant properties of an exopolysaccharide produced by Alteromonas infernus. Biochim Biophys Acta 1528: 141-151

Collin M, Fischetti VA (2004) A novel secreted endoglycosidase from Enterococcus faecalis with activity on human immunoglobulin G and Ribonuclease B. J Biol Chem 279: 22558-22570

Eckert C, Lecerf M, Dubost L, Arthur M, Mesnage S (2006) Functional analysis of AtlA, the major N-acetylglucosaminidase of Enterococcus faecalis. J Bacteriol 188: 8513-8519

Goda HM, Ushigusa K, Ito H, Okino N, Narimatsu H, Ito M (2008) Molecular cloning, expression, and characterization of a novel endo- $\alpha-\mathrm{N}$-acetylgalactosaminidase from Enterococcus faecalis. Biochem Biophys Res Commun 375: 541-546

Guezennec J (2002) Deep-sea hydrothermal vents: a new source of innovative bacterial exopolysaccharides of biotechnological interest? J Ind Microbiol Biotechnol 29: 204-208

Guezennec J, Pignet P, Lijour Y, Gentric E, Ratiskol J, Colliec-Jouault S (1998) Sulfation and depolymerization of a bacterial exopolysaccharide of hydrothermal origin. Carbohydr Polym 37: $19-24$

Karlsson A, Singh SK (1999) Acid hydrolysis of sulphated polysaccharides. Desulphation and the effect on molecular mass. Carbohydr Polym 38: 7-15

Koutsioulis D, Landry D, Guthrie EP (2008) Novel endo-\{alpha\}-N-acetylgalactosaminidases with broader substrate specificity. Glycobiology 18: 799-805

Kumar ABV, Tharanathan RN (2004) A comparative study on depolymerization of chitosan by proteolytic enzymes. Carbohydr Polym 58: 275-283

Kumar ABV, Varadaraj MC, Lalitha RG, Tharanathan RN (2004) Low molecular weight chitosans: preparation with the aid of papain and characterization. Biochim Biophys Acta 1670: 137-146

Nankai H, Hashimoto W, Miki H, Kawai S, Murata K (1999) Microbial system for polysaccharide depolymerization: enzymatic route for xanthan depolymerization by Bacillus sp. strain GL1. Appl Environ Microbiol 65: 2520-2526

Nardella A, Chaubet F, Boisson-Vidal C, Blondin C, Durand P, Jozefonvicz J (1996) Anticoagulant low molecular weight fucans produced by radical process and ion exchange 
chromatography of high molecular weight fucans extracted from the brown seaweed Ascophyllum nodosum. Carbohydr Res 289: 201-208

Paulsen IT, Banerjei L, Myers GSA, Nelson KE, Seshadri R, Read TD, Fouts DE, Eisen JA, Gill SR, Heidelberg JF, Tettelin H, Dodson RJ, Umayam L, Brinkac L, Beanan M, Daugherty S, DeBoy RT, Durkin S, Kolonay J, Madupu R, Nelson W, Vamathevan J, Tran B, Upton J, Hansen T, Shetty J, Khouri H, Utterback T, Radune D, Ketchum KA, Dougherty BA, Fraser CM (2003) Role of mobile DNA in the evolution of vancomycin-resistant Enterococcus faecalis. Science 299: 2071-2074

Raguenes G, Cambon-Bonavita MA, Lohier JF, Boisset C, Guezennec J (2003) A novel, highly viscous polysaccharide excreted by an Alteromonas isolated from a deep-sea hydrothermal vent shrimp. Curr Microbiol 46: 448-452

Raguenes G, Christen R, Guezennec J, Pignet P, Barbier G (1997a) Vibrio diabolicus sp. nov., a new polysaccharide-secreting organism isolated from a deep-sea hydrothermal vent polychaete annelid, Alvinella pompejana. Int J Syst Bacteriol 47: 989-995

Raguenes G, Pignet P, Gauthier G, Peres A, Christen R, Rougeaux H, Barbier G, Guezennec J (1996) Description of a new polymer-secreting bacterium from a deep-sea hydrothermal vent, Alteromonas macleodii subsp. fijiensis, and preliminary characterization of the polymer. Appl Environ Microbiol 62: 67-73

Raguenes GH, Peres A, Ruimy R, Pignet P, Christen R, Loaec M, Rougeaux H, Barbier G, Guezennec JG (1997b) Alteromonas infernus sp. nov., a new polysaccharide-producing bacterium isolated from a deep-sea hydrothermal vent. J Appl Microbiol 82: 422-430

Rigouin C, Delbarre Ladrat C, Sinquin C, Colliec-Jouault S, Dion M (2009) Assessment of biochemical methods to detect enzymatic depolymerization of polysaccharides. Carbohydr Polym 76: $279-284$

Roger O, Kervarec N, Ratiskol J, Colliec-Jouault S, Chevolot L (2004) Structural studies of the main exopolysaccharide produced by the deep-sea bacterium Alteromonas infernus. Carbohydr Res 339: 2371-2380

Roubroeks JP, Andersson R, Mastromauro DI, Christensen BE, Aman P (2001) Molecular weight, structure and shape of oat (1-3),(1-4)-beta-D-glucan fractions obtained by enzymatic degradation with (1-4)-beta-D-glucan 4 glucanohydrolase from Trichoderma reesei. Carbohydr Polym 46: 275-285

Rougeaux H, Guezennec J, Carlson RW, Kervarec N, Pichon R, Talaga P (1999a) Structural determination of the exopolysaccharide of Pseudoalteromonas strain HYD 721 isolated from a deep-sea hydrothermal vent. Carbohydr Res 315: 273-285

Rougeaux H, Kervarec N, Pichon R, Guezennec J (1999b) Structure of the exopolysaccharide of Vibrio diabolicus isolated from a deep-sea hydrothermal vent. Carbohydr Res 322: 40-45

Rougeaux H, Talaga P, Carlson RW, Guezennec J (1998) Structural studies of an exopolysaccharide produced by Alteromonas macleodii subsp. fijiensis originating from a deepsea hydrothermal vent. Carbohydr Res 312: 53-59 
Senni K, Pereira J, Gueniche F, Delbarre-Ladrat C, Sinquin C, Ratiskol J, Godeau G, Fischer AM, Helley D, Colliec-Jouault S (2011) Marine polysaccharides: A source of bioactive molecules for cell therapy and tissue engineering. Mar Drugs 9: 1664-1681

Shively JE, Conrad HE (1976) Formation of anhydrosugars in the chemical depolymerization of heparin. Biochemistry 15: 3932-3942

Sillanpää J, Xu Y, Nallapareddy SR, Murray BE, Höök M (2004) A family of putative MSCRAMMs from Enterococcus faecalis. Microbiology 150: 2069-2078

Stern R, Kogan G, Jedrzejas MJ, Soltes L (2007) The many ways to cleave hyaluronan. Biotechnol Adv 25: 537-557

Sutherland IW (1998) Novel and established applications of microbial polysaccharides. Trends Biotechnol 16: 41-46

Sutherland IW (1999) Polysaccharases for microbial exopolysaccharides. Carbohydr Polym 38: 319-328

Vishu Kumar AB, Varadaraj MC, Gowda LR, Tharanathan RN (2007a) Low molecular weight chitosans preparation with the aid of pronase, characterization and their bactericidal activity towards Bacillus cereus and Escherichia coli. Biochim Biophys Acta 1770: 495-505

Vishu Kumar BA, Varadaraj MC, Tharanathan RN (2007b) Low molecular weight chitosanpreparation with the aid of pepsin, characterization, and its bactericidal activity. Biomacromolecules 8: 566-572

Volpi N (1994) Dermatan sulfate from beef mucosa: structure, physicochemical and biological properties of fractions prepared by chemical depolymerization and anion-exchange chromatography. Carbohydr Res 255: 133-144

Zanchetta P, Lagarde N, Guezennec J (2003) A new bone-healing material: a hyaluronic acid-like bacterial exopolysaccharide. Calc Tissue Int 72: $74-79$ 
Table 1: Commercial enzymes screened for the HE800 depolymerising activity.

\begin{tabular}{|c|c|c|}
\hline Enzyme & Manufacturer & Reference \\
\hline Alginate lyase & CEVA & AL651 \\
\hline Alpha-amylase & Sigma & A7720 \\
\hline Alpha-glucosidase & Sigma & G3651 \\
\hline Amyloglucosidase & Sigma & A9913 \\
\hline Beta-amylase & Sigma & A7005 \\
\hline Beta-galactosidase & Sigma & G5190 \\
\hline Beta-glucosidase (almonds) & Sigma & G0395 \\
\hline Beta-glucuronidase & Sigma & G7396 \\
\hline Beta-glucuronidase & Sigma & G7646 \\
\hline Bromelain & Sigma & B2252 \\
\hline Celluclast $1,5 \mathrm{~L}$ & Novozymes & CCN030502 \\
\hline Cellulase & Sigma & A8546 \\
\hline Cellulase & Sigma & C9422 \\
\hline Cellulase A & Amano & \\
\hline Chitinase & Sigma & C6137 \\
\hline Chitinase & Sigma & C6137 \\
\hline Chondroitinase AC & Sigma & C2780 \\
\hline Endo-alpha-L- $\mathrm{N}$-acetylgalactosaminidase & Calbiochem & 324716 \\
\hline Heparinase III & Sigma & H8891 \\
\hline Hyaluronate lyase & Sigma & $\mathrm{H} 1136$ \\
\hline Hyaluronidase II (sheep) & Sigma & H2126 \\
\hline Hyaluronidase III (bovine) & Sigma & H3506 \\
\hline Hyaluronidase III (sheep) & Sigma & H2251 \\
\hline Lysing enzyme & Sigma & L1412 \\
\hline Lysosyme & Sigma & L6876 \\
\hline Papain & Sigma & P3250 \\
\hline soluble Papain & Merck & 7147 \\
\hline Pectinase & Sigma & P4716 \\
\hline Pectinex Ultra SP-L & Sigma & P2611 \\
\hline Pectolyase & Sigma & P3026 \\
\hline Pepsin & Sigma & P6887 \\
\hline Pronase & Sigma & P8811 \\
\hline Protease type IV & Sigma & P5147 \\
\hline Proteinase $\mathrm{K}$ & Sigma & P8044 \\
\hline Pulpzyme HC & Novozymes & CKN00044 \\
\hline Subtilisin A & Sigma & P5380 \\
\hline Trypsin & Sigma & T8128 \\
\hline Viscozyme L & Sigma & V2010 \\
\hline
\end{tabular}

Alginate lyase was supplied by "Centre de Valorisation des Algues" (CEVA, France); Celluclast and Pulpzyme were a kind gift from Novozymes. 
Table 2: Microorganisms from Ifremer, Nantes University and Nantes Hospital collections as wellas from public collections used for the screening for the depolymerisation of the EPS HE800

\begin{tabular}{|c|c|c|}
\hline Origin & Strain & Medium \\
\hline \multirow{12}{*}{$\begin{array}{l}\text { Deep sea hydrothermal vents } \\
\text { (Ifremer collection) }\end{array}$} & Alteromonas macleodii subsp. fijiensis ST716 & $\mathrm{Z}$ \\
\hline & Alteromonas macleadii subsp. fijiensis HYD 708 & $\mathrm{Z}$ \\
\hline & Alteromonas macleodï subsp. fïiensis HYD657 & $\mathrm{Z}$ \\
\hline & Pseudoalteromonas HYD721 & $\mathrm{Z}$ \\
\hline & Alteromonas HYD1545 & $\mathrm{Z}$ \\
\hline & Altermmonas HYD1644 & $\mathrm{Z}$ \\
\hline & Alteromonas infernus GY785 & $\mathrm{Z}$ \\
\hline & Unidentified strain MS 941 & $\mathrm{Z}$ \\
\hline & Unidentified strain MS 960 & $\mathrm{Z}$ \\
\hline & Alteromonas macleadii subsp. fijiensis MS907 & $\mathrm{Z}$ \\
\hline & Unidentified strain MS932 & $\mathrm{z}$ \\
\hline & Vibrio diabolicus HE800 & $\mathrm{Z}$ \\
\hline \multirow[t]{7}{*}{ Marine (Public collections) } & Alteromonas espejiana LMG 2866 & $\mathrm{Z}$ \\
\hline & Alteromonas undina $L M G 2880$ & $\mathrm{Z}$ \\
\hline & Alteromonas carrageenovora LMG 2154 & $\mathrm{Z}$ \\
\hline & Alteromonas haloplanktis LMG 2852 & $\mathrm{z}$ \\
\hline & Vibrio alginolyticus LMG 4409 & $\mathrm{Z}$ \\
\hline & Vibrio parahaemolyticus LMG 2850 & $\mathrm{Z}$ \\
\hline & Vibrio campbellï LMG 11216 & $\mathrm{Z}$ \\
\hline \multirow{10}{*}{$\begin{array}{l}\text { Lake dwelling (Bogoria, Kenya, Nantes } \\
\text { University collection) }\end{array}$} & Bacillus pumilus $\mathrm{B} 6$ & LB \\
\hline & Bacillus licheniformis A53 & LB \\
\hline & Bacillus lautus F2 & LB \\
\hline & Bacillus halodurans $\mathrm{B} 9$ & LB \\
\hline & Bacillus subtilis & LB \\
\hline & Bacillus pseudofirmus & LB \\
\hline & Unidentified strain $\mathrm{H} 3$ & LB \\
\hline & Unidentified strain H5 & LB \\
\hline & Unidentified strain $\mathrm{H} 6$ & LB \\
\hline & Vibrio metchnikovii & LB \\
\hline \multirow{10}{*}{$\begin{array}{l}\text { Infectious (human samples, Nantes } \\
\text { Hospital collection) }\end{array}$} & Bacillus stearothermophilus & LB \\
\hline & Enterobacter cloacae & LB \\
\hline & Enterococcus faecalis SP1 & LB \\
\hline & Enterococcus faecium & LB \\
\hline & Pseudomonas aeruginosa & LB \\
\hline & Pseudomonas cepacia & LB \\
\hline & Staphylococcus aureus & LB \\
\hline & Staphylacoccus epidermis & LB \\
\hline & Staphylacoccus $H$ & LB \\
\hline & Staphylococcus hominis & LB \\
\hline \multirow[t]{3}{*}{ Others (Public collection) } & Bacillus circulans DSM7257 & LB \\
\hline & Agrobacterium tumefaciens C58 CIP 104333 & LB \\
\hline & Enterococcus faecalis V583 CIP 106998 & LB \\
\hline
\end{tabular}

Public collections: LMG Universiteit Gent, Laboratorium voor Mikrobiologie, Ghent, Belgium; DSM DSMZ, Braunschweig, Germany; CIP Institut Pasteur, Paris, France. LB: Luria broth; Z: Zobell. 
Table 3: Listing by E. faecalis V583 genome annotation, of glycoside hydrolases/lyases potentially involved in the depolymerisation of the EPS HE800..

\begin{tabular}{llll}
\hline Reference & Name & Potential family $(\mathrm{CAZY})$ & Enzymatic activity \\
\hline EF0114 & Glycoside hydrolase & Family $20 \mathrm{GH}$ & Endo- $\beta$ - $N$-acetyl-glucosaminidase* \\
EF0361 & Chitinase & Family $2 \mathrm{GH}$ & $\beta$ - $N$-acetyl-glucosaminidase \\
EF0551 & Glycoside hydrolase & Family $31 \mathrm{GH}$ & $\alpha$-Glucan lyase \\
EF0799 & Autolysine (AltA) & -- & Endo- $\beta$ - $N$-acetyl-glucosaminidase* \\
EF0818 & Ppolysaccharide lyase & Family $8 \mathrm{PL}$ & Xanthan lyase / hyaluronate lyase \\
EF1800 & Glycoside hydrolase & Family $101 \mathrm{GH}$ & Endo- $\alpha$ - $N$-acetyl-galactosaminidase* \\
EF1824 & Glycoside hydrolase & Family $31 \mathrm{GH}$ & $\alpha$-Glucan lyase \\
EF2863 & Endo $\beta$-N-acetyl-glucosaminidase & Family $18 \mathrm{GH}$ & Endo $\beta$ - $N$-acetyl-galactosaminidase \\
EF3023 & Polysaccharide lyase & Family $8 \mathrm{PL}$ & Xanthan lyase / hyaluronate lyase \\
\hline
\end{tabular}

Upon looking at the structure of the polysaccharide, 7 proteins were selected for extensive bioinformatic studies (in grey). CAZY potential family: http://www.cazy.org. (GH: glycoside hydrolase; $P L$ : polysaccharide lyase)

* Enzymatic activity experimentally confirmed (Collin and Fischetti 2004; Eckert et al. 2006; Goda et al. 2008; Koutsioulis et al. 2008) 
Fig. 1: Depolymerisation of the EPS HE800 by E. faecalis SP1 lysate. Lysed cells at the end of the exponential phase culture of E. faecalis were concentrated and incubated with HE800 at $2 \mathrm{mg}$ $\mathrm{ml}^{-1}$. Collected samples were analysed for HE800 depolymerisation. A Electrophoretic analysis of the samples at 0, 4, 24, 72, 144 and $196 \mathrm{~h}$ incubation. B Molecular weight of the HE800 determined by SEC-MALS at the same time points

A

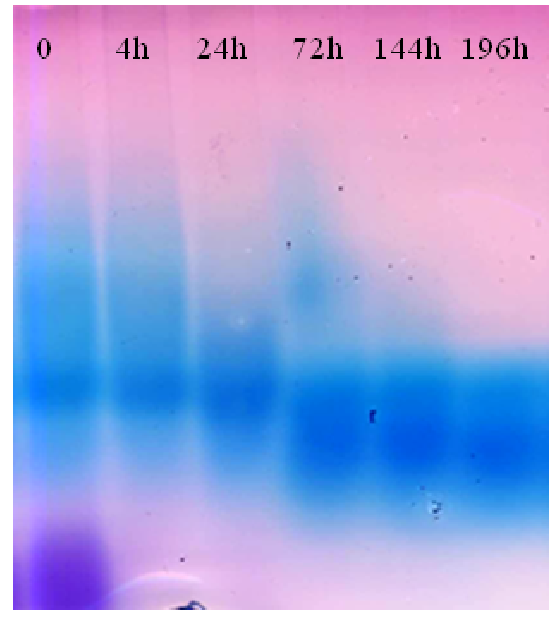

B

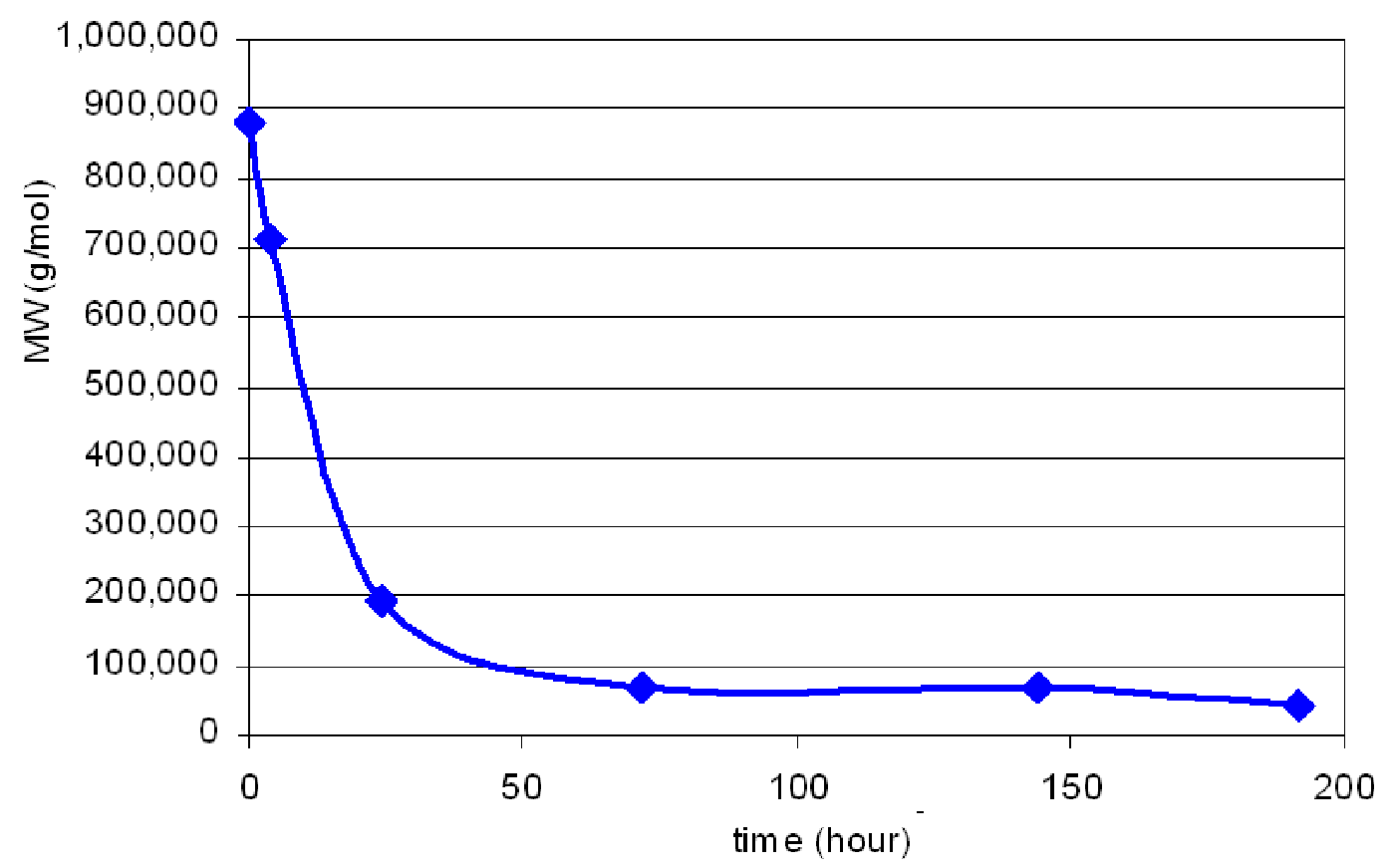


Fig.2: SEC-MALS analysis: refractive index (RI) (bottom curves) and logarithm of the molecular weight $\left(\log M_{\mathrm{w}}\right)$ (top curves) versus elution time, for the incubation of the EPS HE800 with lysate of E. faecalis SP1

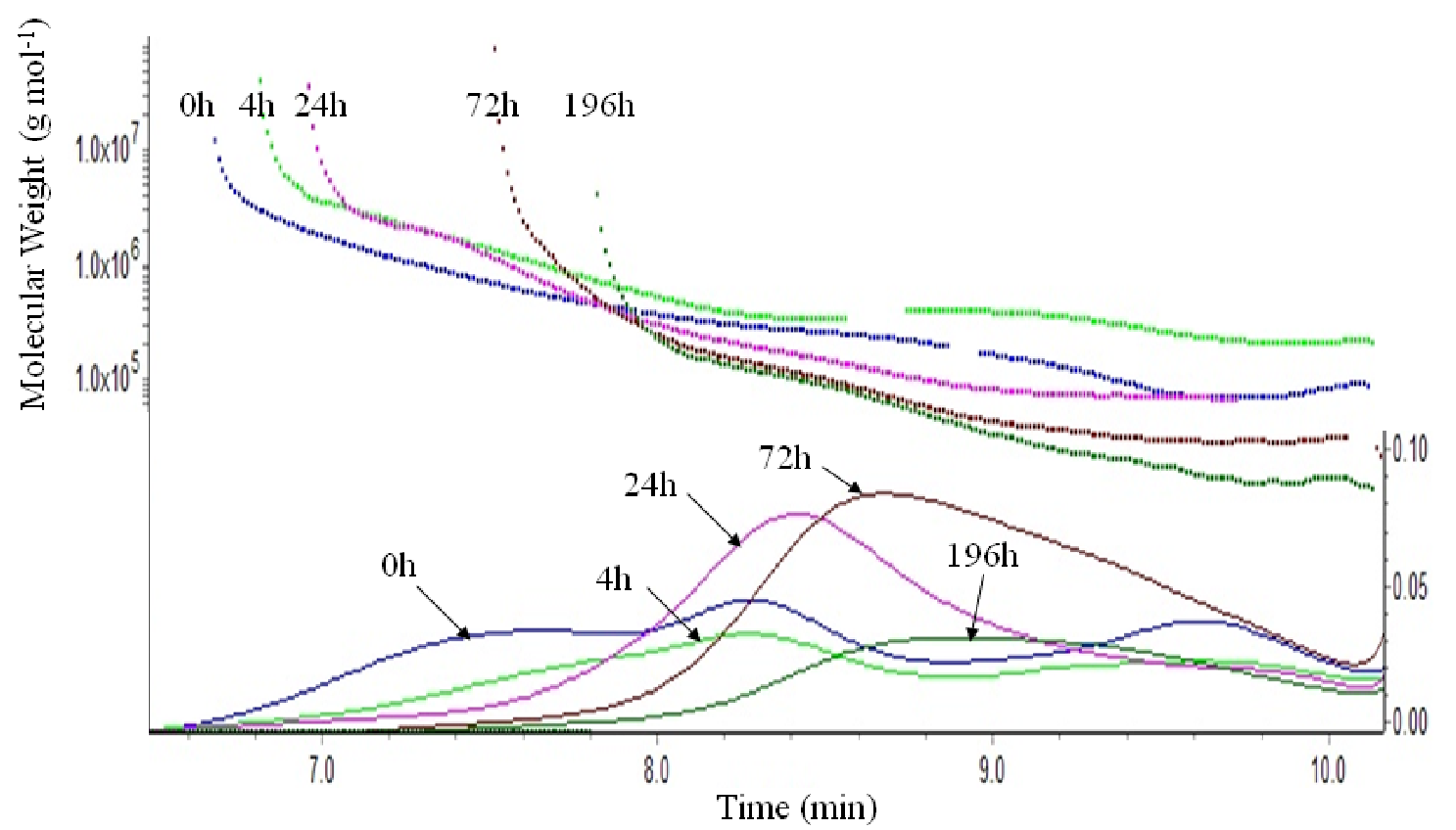

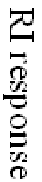


Fig. 3: Enzymatic activity of the lysed cells of E. faecalis SP1 (diamond) and E. faecalis V583 (square) on HE800. $k$, rate constant of the depolymerisation process, is given by the slope of the curve

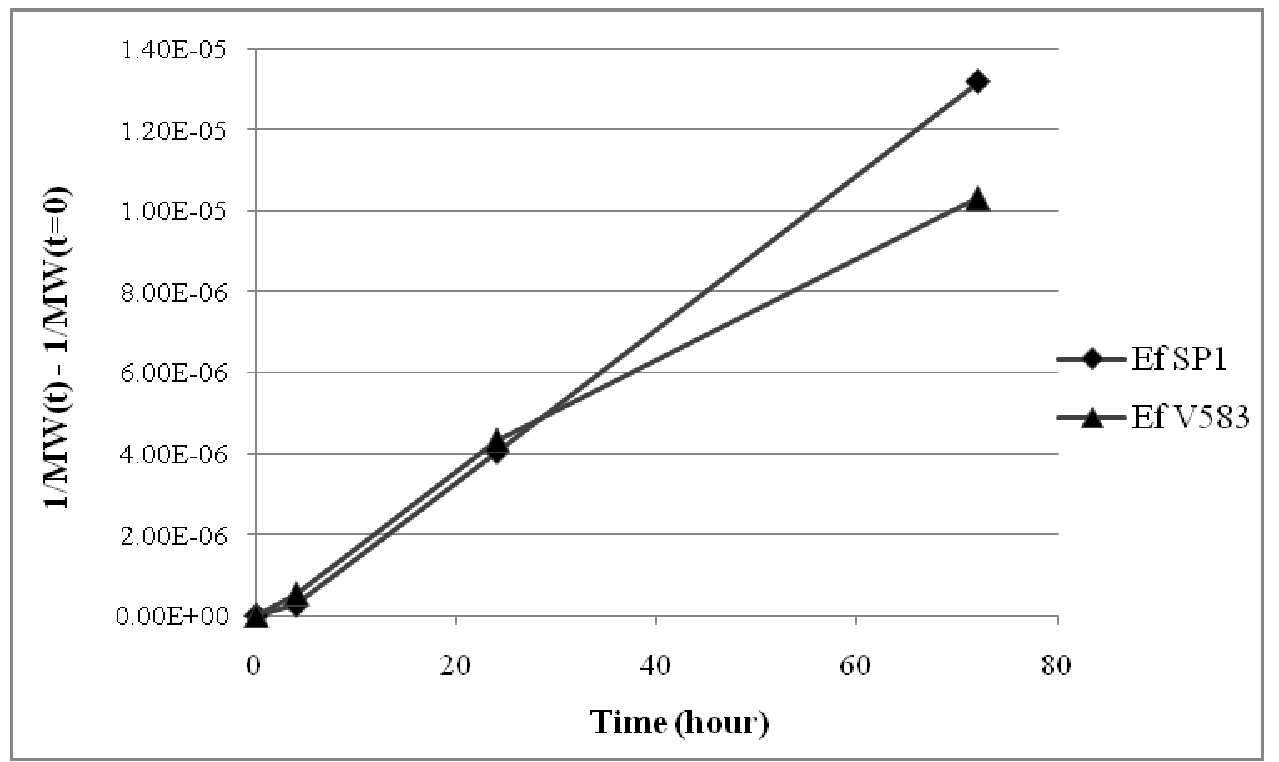


Fig. 4: Depolymerisation of the EPS HE800 by E. faecalis EF1800 enzyme: agarose electrophoresis analysis (A) and RI response obtained by SEC-MALS (B). The reaction was performed in the NEB denaturation buffer with the preheated HE800 at $1 \mathrm{mg} \mathrm{mL}^{-1}$ and the enzyme EF1800 during $72 \mathrm{~h}$ at $37^{\circ} \mathrm{C}$. Incubation times were 0,40 and $72 \mathrm{hs.} \mathrm{A} \mathrm{control} \mathrm{without} \mathrm{enzyme}$ was carried out

A

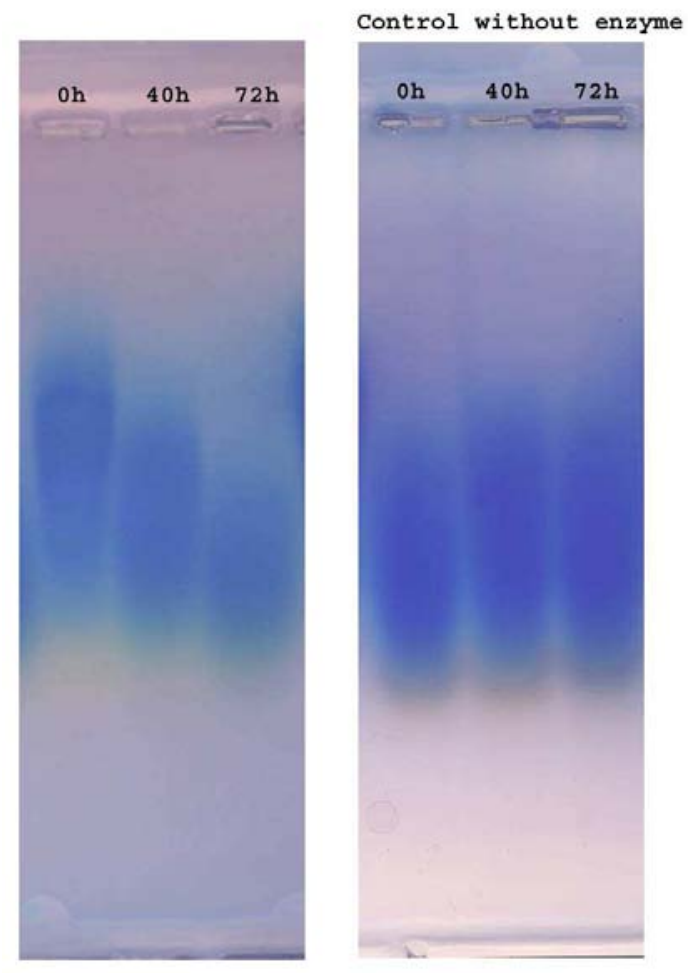

\section{B}
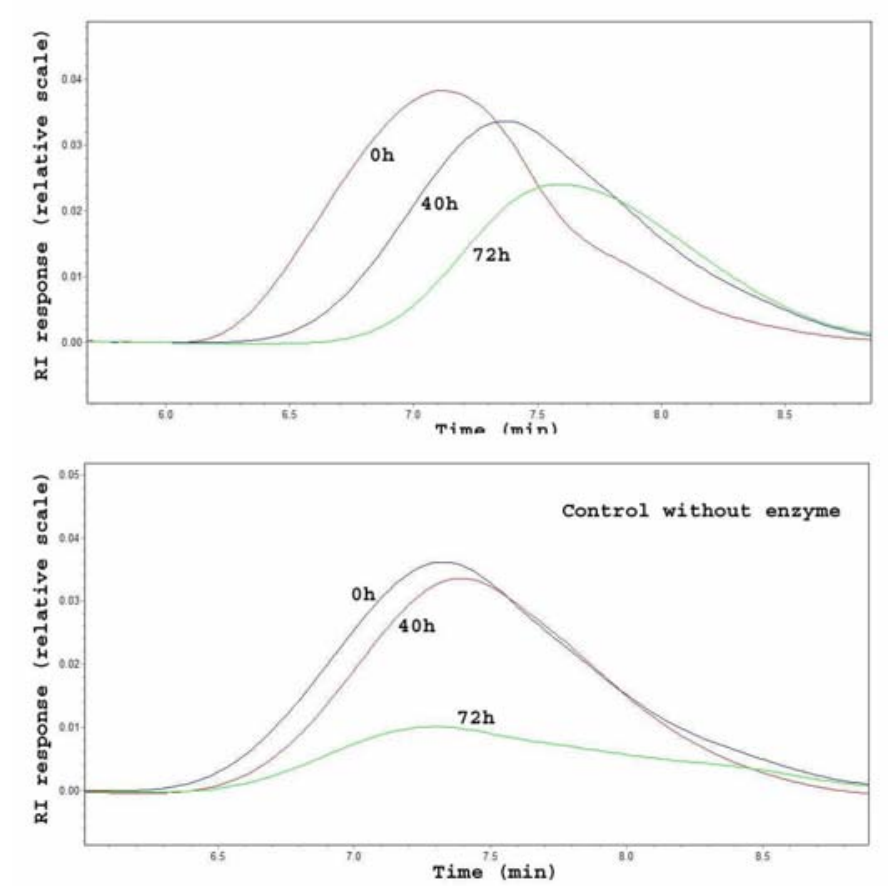